\title{
INDEKS KEANEKARAGAMAN JENIS IKAN DEMERSAL DI PERAIRAN TARAKAN
}

\section{BIODIVERSITY INDICES OF DEMERSAL FISH IN TARAKAN WATERS}

\author{
Suprapto \\ Peneliti pada Balai Penelitian Perikanan Laut Jakarta \\ Teregistrasi I tanggal: 30 Oktober 2014; Diterima setelah perbaikan tanggal: 21 Maret 2014; \\ Disetujui terbit tanggal: 04 April 2014 \\ E-mail:prapsuradi01@yahoo.com
}

\begin{abstract}
ABSTRAK
Perairan Tarakan termasuk daerah penangkapan sumber daya ikan demersal dan udang cukup potensial di Kalimantan Utara. Tingginya tingkat eksploitasi ikan demersal dengan menggunakan trawl menyebabkan keragaman jenisnya rendah. Penelitian ikan demersal dilakukan di perairan Tarakan pada bulan Mei, Agustus dan Nopember 2012. Tujuan penelitian adalah untuk memperoleh indeks keanekaragaman jenis ikan demersal. Data spesies ikan demersal dikumpulkan dari hasil tangkapan jaring trawl yang dioperasikan oleh kapal motor 20GT dengan metode sapuan area. Hasil penelitian menunjukkan bahwa jumlah taksa ikan demersal sebanyak 86 spesies yang tergolong kedalam 45 famili. Komposisi jenis hasil tangkapan trawl didominasi oleh famili Leiognathidae (ikan petek), Sciaenidae (ikan gulama), Harpadontidae (ikan nomei), Apogonidae (ikan serinding) dan Mullidae (ikan bijinangka). Status keanekaragaman jenis termasuk dalam kategori sedang dengan indeks "Shanon-Wiener" (H') berkisar antara 1,7-2,5 sedangkan indeks kekayaan "Margalef" $\left(\mathrm{R}_{1}\right)$ berkisar antara 7-8. Penyebaran spesies ikan demersal bersifat sedang dengan indeks kemerataan jenis (E) rata-rata sebesra 0,5. Kelimpahan ikan demersal tidak ada yang dominan, ditunjukkan oleh nilai indeks kemerataan jenis "Pielou" (E) rata-rata sebesar 0,4.
\end{abstract}

KATA KUNCI: Indek keanekaragaman, ikan demersal, perairan Tarakan.

\section{ABSTRACT}

Tarakan and adjacent waters is one of potentially fishing ground of demersal fish resources in north Kalimantan. High exploitation by trawler tend to decreased of biodiversity of demersal fish in this area. Research has been conducted in the waters of Tarakan during May, August and November 2012. The aim of this research is to get species diversity indices of demersal fish, which is expected to be useful as one of the data capacity for sustainable fisheries management policy. Data obtained by using trawl fishing gear with a sweept area method. The results showed that demersal fish species richness 86 species, belonging to 45 families. Dominant family are Leiognathidae, Sciaenidae, Harpadontidae, Apogonidae and Mullidae. Result of analysis indicate that species diversity in Tarakan waters in the medium category. Status of biodiversity consist of: range value diversity indices "Shanon-Wiener" ( $\mathrm{H}$ ') was 1.7 to 2.5; species richness indices of "Margalef" $\left(R_{1}\right)$ are between 7-8; evenness indices of "Pielou" (E 1) was 0,5 and dominant indices "Pielou" $(E)$ an average of 0.4.

KEYWORDS: Diversity indices, demersal fish, Tarakan waters

\section{PENDAHULUAN}

Indeks keanekaragaman jenis ikan merupakan nilai tunggal yang mencerminkan karakterisasi dari hubungan kelimpahan individu di antara spesies dalam komunitas sumber daya ikan (Ludwig \& Reynold, 1988). Keanekaragaman jenis dipengaruhi oleh faktor eksternal (tekanan eksploitasi, degradasi lingkungan, pencemaran) atau faktor internal (pemangsaan dan persaingan antar spesies) (Odum,1971). Indeks bernilai tinggi sebagai indikasi komunitas dalam lingkungan yang mantap dan stabil, kondisi sebaliknya sebagai petunjuk lingkungan yang labil dan berubah-ubah. Berdasarkan konsep tersebut maka tersedianya data indeks keanekaragaman jenis ikan di perairan Tarakan, dapat digunakan sebagai salah satu referensi bagi studi lanjutan, maupun dapat dipertimbangkan sebagai salah satu data dukung untuk penetuan kebijakan pengelolaan perikanan yang berkelanjutan.

Tingginya eksploitasi ikan demersal di Kalimantan Utara khususnya Tarakan dan sekitarnya dengan alat tangkap trawl dan sejenisnya sudah diketahui dari hasil penelitian sebelumnya (Naamin, 1977; Sumiono \& Priyono,1998, Barus \& Mahiswara, 1994; Sumiono \& Djamali, 2006). Komposisi jenis, laju tangkap dan daerah penangkapan ikan demersal di perairan Tarakan dan sekitarnya dilaporkan juga dari survey trawl pada tahun 2005 oleh Mulyadi et al. (2005).

Tulisan ini membahas tentang indeks keanekaragaman jenis ikan demersal di perairan Tarakan akibat tekanan eksploitasi yang berlebihan. 


\section{BAHANDANMETODE}

Penelitian ikan demersal dilakukan pada bulan Mei, Agustus dan Nopember 2012 di perairan Pulau Tarakan dan sekitarnya (Gambar1). Data spesies ikan demersal diperoleh dari hasil tangkapan lampara dasar (trawl mini) yang dioperasikan oleh kapal motor 20GT dengan metode. swept area (Sparre \& Venema, 1992). Jaring trawl mempunyai panjang tali ris atas (head rope) $26 \mathrm{~m}$, tali ris bawah (ground rope) $28 \mathrm{~m}$ dan ukuran mata jaring pada bagian kantong (cod end) 1 inchi. Penangkapan dilakukan pada siang hari. Identifikasi ikan demersal mengacu kepada Allen et.al (2000), Carpenter \& Niem (1999 a,b dan 2001a,b), Gloefer-Tarp \& Kailola (1985); Nakabo (2000); Donald (1981), Fischer \& Whitehead (1974), Heemstra \& Rendall (1973), Mansoor et. al.(1998).

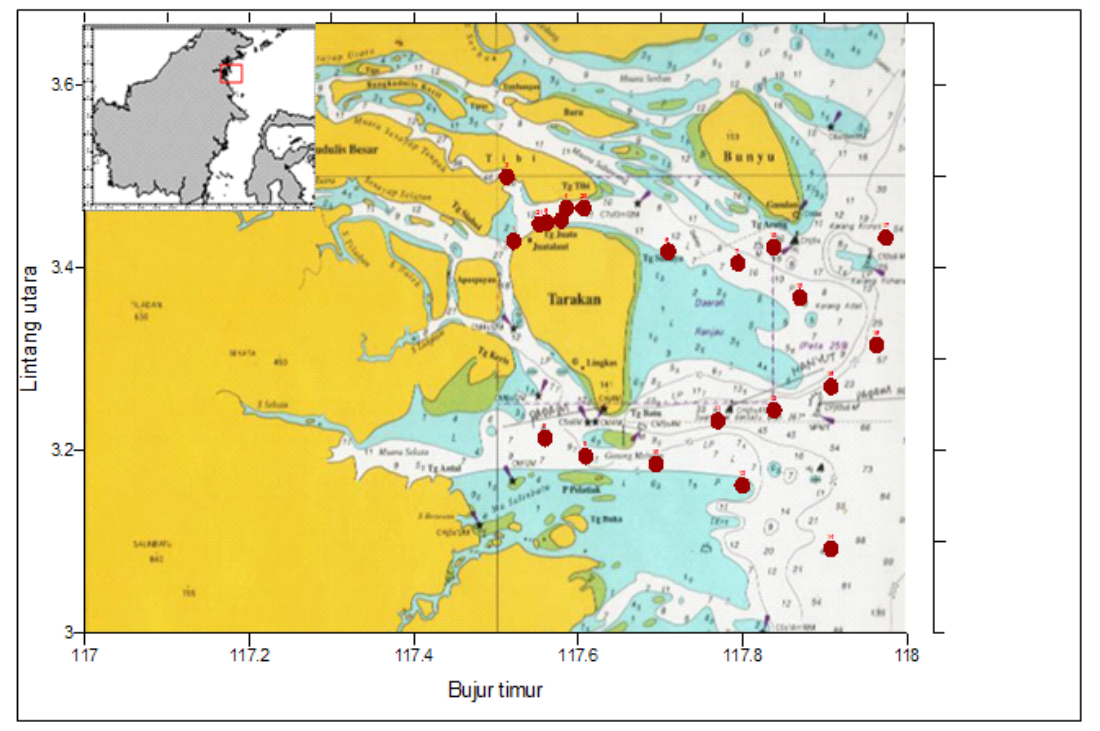

Gambar 1. Peta lokasi penelitian $(\bullet=$ posisi stasiun penangkapan)

Figure 1. The maps of research location $(\bullet=$ fishing positions)

Analisis indeks keanekaragaman hayati mengikuti model matematis menurut Odum (1971), Pielou (1976), Ludwig \& Reynold (1988), dan Krebs (1989) dengan rumus sebagai berikut:

a. Indeks keanekaragaman jenis (species diversity) Shannon-Wiener (Odum (1971) : $\mathbf{H}^{\mathbf{1}}=$ - å $\left[\left(\mathbf{n}_{\mathbf{i}} / \mathbf{N}\right) /\right.$ $\operatorname{Ln}\left(\mathbf{n}_{\mathbf{i}} / \mathbf{N}\right)$ ], dimana $\mathbf{N}=$ total individu ikan untuk semua spesies dan $\mathbf{n}_{\mathbf{i}}=$ jumlah ikan untuk spesies ke $i$.

b. Indeks kelimpahan (Diversity numbers) Hill : $\mathbf{N}_{\mathbf{1}}=$ $\mathbf{e}^{\mathbf{H}}$ dan $\mathbf{N}_{2}=\mathbf{1} / \mathbf{l}$, dimana $\mathbf{l}=$ indeks Simpson $=" n i *(n i-1) / \mathrm{N}(\mathrm{N}-1), \quad \mathbf{N}_{1}$ ditafsirkan sebagai banyaknya spesies yang melimpah, sedangkan $\mathbf{N}_{2}$ banyaknya spesies yang paling melimpah; $\mathbf{H}^{\mathbf{1}}=$ indeks Shannon; dan $\boldsymbol{e}=$ bilangan natural $(=2,718)$

c. Indeks Indeks kekayaan jenis (species richness) "Margalef" : $\mathbf{R}_{\mathbf{1}}=(\mathbf{S}-\mathbf{1}) / \mathbf{L n}(\mathbf{N})$, dimana " $\mathrm{S}$ " = banyaknya species dan "N" = jumlah individu ikan untuk semua species.

d. Indeks kemerataan (species evenness) Pielou (1976) : $\mathbf{E}_{\mathbf{1}}=\mathbf{H}^{\prime} / \mathbf{L n}$ (s), dimana $\mathbf{S}=$ banyaknya spesies, H'= indeks Shannon- Wiener e. Indeks dominansi jenis (species dominant) $\mathrm{C}=\sum\left[\frac{\mathrm{n}_{\mathrm{i}}}{\mathrm{N}}\right]^{2}$ dimana $\mathbf{n}_{\mathrm{i}}=$ jumlah ikan untuk spesies ke $i ; \quad \mathbf{N}=$ jumlah total individu semua spesies

\section{HASIL DAN BAHASAN}

HASIL

\section{Komposisi Jenis Ikan Demersal}

Dari 86 jenis ikan demersal yang tertangkap terdapat sepuluh famili ikan yang dominan berdasarkan jumlah individu yang tertangkap (Tabel 1). Kelompok ikan peperek (famili Leiognathidae) dan ikan gulama (Sciaenidae) mendominasi hasil tangkapan. Spesies ikan peperek yang paling dominan adalah Leiognathus splendens.

\section{Kekayaan Jenis}

Hasil tangkapan ikan demersal diperoleh 86 spesies yang tergolong kedalam 45 famili. Kekayaan jenis terbanyak diperoleh pada bulan Agustus dan Nopember, sebaliknya terendah pada bulan Mei (Tabel 2). 
Tabel 1. Sepuluh family dominan ikan demersal yang tertangkap trawl di perairan Tarakan bulan mei, agustus dan Nopember 2012

Table 1. The ten dominant families of demersal fish caught by trawl in Tarakan waters during May, August and November 2012

\begin{tabular}{|c|c|c|c|c|c|}
\hline \multicolumn{2}{|c|}{ MEI } & \multicolumn{2}{|c|}{ AGUSTUS } & \multicolumn{2}{|c|}{ NOPEMBER } \\
\hline Famili & $\%$ & Famili & $\%$ & Famili & $\%$ \\
\hline Scianidae & 43,0 & Leiognathidae & 86,7 & Leiognathidae & 63,3 \\
\hline Leiognathidae & 38,8 & Sciaenidae & 4,5 & Sciaenidae & 20,2 \\
\hline Harpadontidae & 6,4 & Apogonidae & 2,0 & Mullidae & 3,0 \\
\hline Ariidae & 3,0 & Mullidae & 1,9 & Apogonidae & 2,8 \\
\hline Gerreidae & 1,7 & Harpadontidae & 1,1 & Harpadontidae & 2,5 \\
\hline Polynemidae & 1,2 & Gerreidae & 1,1 & Gerreidae & 1,4 \\
\hline Mullidae & 1,0 & Polynemidae & 0,6 & Ariidae & 1,3 \\
\hline Cynoglossidae & 0,8 & Tetraodontidae & 0,3 & Nemipteridae & 0,9 \\
\hline Ephippidae & 0,6 & Trichyuridae & 0,3 & Cynoglossidae & 0,8 \\
\hline Haemulidae & 0,6 & Ephippidae & 0,3 & Ephippidae & 0,6 \\
\hline
\end{tabular}

Tabel 2. Jumlah taksa ikan demersal di Tarakan yang tertangkap trawl pada bulan Mei, Agustus dan Nopember 2012.

Table 2. Number of taxa of demersal fish, caught by trawl in Tarakan waters, May, August and November 2012

\begin{tabular}{lcc}
\hline \multirow{2}{*}{ Bulan (Month) } & \multicolumn{2}{c}{$\begin{array}{c}\text { Jumlah taksa ikan demersal } \\
\text { (Number of taxa of demersal fish) }\end{array}$} \\
\cline { 2 - 3 } Mei (May) & Suku $($ family) & Jenis (species) \\
Agustus (August) & 34 & 66 \\
Nopember (November) & 45 & 86 \\
\hline TOTAL & 39 & 86 \\
\hline
\end{tabular}




\section{Indeks Keanekaragaman}

Hasil perhitungan beberapa parameter struktur komunitas ikan demersal diperoleh nilai indeks keanekaragaman jenis seperti tercantum pada Tabel 3. Tampak bahwa nilai indeks keanekaragaman ShannonWiener $\left(\mathrm{H}^{1}\right)$, berkisar antara 1,7-2,5. Menurut Krebs (1989) komunitas di perairan ini berada dalam kategori keragaman “sedang”, karena nilai H' berada pada kisaran antara 1-3

Status indeks kekayaan jenis dari Margalef $\left(\mathrm{R}_{1}\right)$ berkisar antara 7-8, merupakan gambaran kekayaan jenis di perairan ini termasuk kategori rendah. Indeks kemerataan jenis dari
Pielou (E) berkisar antara 0,4-0,6 atau rata-rata 0,5 Nilai tersebut menggambarkan sifat penyebaran diantara jenis bersifat sedang. Nilai indeks dominasi $(\mathrm{C})$ berkisar antara 0,3-0,5 atau rata-rata 0,4 yang mencerminkan tidak banyak spesies yang mendominas atau sifat penyebaran ikan demersal pada umummya merata di perairan Tarakan.

Tabel 4 memperlihatkan perbandingan indeks keanekaragaman jenis dari berbagai perairan di Indonesia. Tampak bahwa, indeks keanekaragaman jenis (H') ikan demersal di perairan Tarakan (antrara 1,7-2,5), hampir sama nilainya dengan Kepulauan Aru, tetapi lebih rendah dibandingkan perairan Selat Makasar dan Laut Arafura.

Tabel 3. Nilai indeks struktur komunitas ikan demersal di perairan Tarakan, bulan Mei, Agustus dan Nopember 2012 Table 3. Value of community structure indeces of demersal fish in Tarakan waters on May, August and Novembre 2012

\begin{tabular}{lccc}
\hline $\begin{array}{c}\text { Parameter } \\
\text { (Paramters) }\end{array}$ & $\begin{array}{c}\text { Mei } \\
\text { (May) }\end{array}$ & $\begin{array}{c}\text { Agustus } \\
\text { (August) }\end{array}$ & $\begin{array}{c}\text { Nopember } \\
\text { (November) }\end{array}$ \\
\hline Jumlah spesies /Number of species $(\mathbf{S})$ & 66 & 86 & 86 \\
Jumlah individu(ekor)/Number of individual $(\mathbf{n})$ & 15.664 & 81.437 & 45.243 \\
Indeks keragaman jenis/species diversity indeces Shannon-Wiener $\left(\mathbf{H}^{\prime}\right)$ & 2,0 & 1,7 & 2,5 \\
Indeks kekayaan jenis/species richness indeces Margalef $\left(\mathbf{R}_{\mathbf{1}}\right)$ & 7 & 8 & 8 \\
Keimpahan jenis/Diversity numbers $\quad$ Hill $\left(\mathbf{N}_{\mathbf{1}}\right)$ & 7 & 5 & 13 \\
Indeks kemerataan/species evenness indeces Pielou $\mathbf{E}$ & 4 & 3 & 8 \\
indeks dominasi (Species dominant indeces) $\mathbf{C}$ & 0,5 & 0,4 & 0,6 \\
\hline
\end{tabular}

Tabel4. Perbandingan indeks keanekaragaman hayati ikan demersal di perairan Selat Makasar, Laut Arafura, Kepulauan Aru dan Tarakan

Table 4. Comparison of biodiversity indices of demersal fish in the Makassar Strait, Arafura Sea, Aru Islands and Tarakan waters

\begin{tabular}{|c|c|c|c|c|}
\hline Parameter Struktur Komunitas & Selat Makasar -1) & Arafura - 2) $\quad \mathrm{K}$ & Kepulauan Aru - 3) & Tarakan \\
\hline (Parametre of community structure) & Makasar Strait & Arafura Sea & Aru Island & Tarakan Island \\
\hline Jumlah spesies /Number of species (S) & 175 & $63-141$ & 138 & $66-86$ \\
\hline Jumlah individu(ekor)/Number of individual (n) & $37815-52435$ & 157182 - 259479 & 712 & $45243-15664$ \\
\hline Indeks keragaman jenis/species diversity indeces Shannon-Wiener (H') & $1,5-3,5$ & $2,24-2,79$ & $0,1-2,5$ & $1,7-2,5$ \\
\hline Indeks kekayaan jenis/species richness indeces $\operatorname{Margalef}\left(\mathbf{R}_{\mathbf{l}}\right)$ & $11-12$ & $5,18-11,23$ & - & $7-8$ \\
\hline Keimpahan jenis/Diversity numbers Hill $\left(\mathrm{N}_{1}\right)$ & $5-35$ & $9,4-16,3$ & - & $5-13$ \\
\hline Indeks kemerataan/species evenness indeces Pielou $\mathbf{E}$ & $0,1-0,3$ & $0,54-0,56$ & $0,1-0,8$ & $0,4-0,6$ \\
\hline
\end{tabular}




\section{BAHASAN}

Nilai kekayaan kekayaan jenis ikan demersal bervariasi menurut berbagai lokasi penangkapan secara spasial sebagaimana tertera pada Tabel 4 , keragaman jenis tertinggi berada di sebelah selatan selat Makasar (Suprapto, 2012), selanjutnya berkurang ke arah utara hingga perairan Tarakan. Menurut Tandipayuk \& Haryati (1986) status (tinggi/rendahnya) keragaman jenis di suatu perairan berkaitan dengan kegiatan penangkapan yang berlangsung di perairan tersebut. Hasil penelitian yang menunjukkan keragaman jenis di sebelah utara dari Selat Makasar (perairan tarakan relatif rendah diduga karena faktor tekanan penangkapan yang semakin berat. Tingginya eksploitasi di perairan tersebut sudah diketahui sejak tahun 2000, dimana tyerdapat peningkatan jumlah unit trawl yang beropersai di perairan antara tarakan dan Nunukan (Mulyadi et al., 2005)

Tampak bahwa status kekayaan jenis ikan demersal di perairan Tarakan (86 spesies tergolong dalam 45 suku) termasuk lebih banyak dibandingkan dengan perairan Bulungan dan Nunukan yaitu 31 famili 45 genus dan 41 famili 73 spesies (Mulyadi et al, 2005; Sadhotomo et al., 2005). Akan tetapi lebih sedikit bila dibandingkan dengan perairan Tanjung Selor, Tanjung Redep (Kab.Berau) dan Balikpapan yang memiliki kelimpahan 84 spesies tergolong 40-57 suku (Sadhotomo, 2005) dan 175 spesies tergolong dalam 59 suku (Suprapto et al, 2012).

Menurut Badrudin et al. (2003), angka-angka indeks keanekaragaman jenis yang telah diperoleh dari hasil perhitungan dan analisis data hasil suatu observasi dapat dipakai sebagai data dasar (base line data) yang dapat digunakan sebagai pembanding (benchmark).

Komposisi hasil tangkapan trawl di perairan tarakan selalu didominasi oleh ikan peperek (famili leiognathidae) dan ikan tigawaj (famili Sciaenidae) (Tabel 2). Hampir sebagian besar hasil tangkapan trawl di beberapa wilayah perairan Indonesia yang padat penangkapannya selalu memperlihatkan ikan petek dan tigawaja mendominasi hasil tangkapan, seperti di Laut Jawa (Suman et al., 2005), Selatan Kalimantan (Sutarto et al., 2007), perairan Aru (Badruddin \& Karyana (1993); BPPL, 2001) dan Aceh (BRPL, 2006). Hal tersebut menunjukkan bahwa ikan petek memiliki laju pertumbuhan yang tinggi sehingga selalu bertahan walaupun sering tertangkap dalam volume yang banyak. Pengaruh tekanan penangkapan dapat memicu perubahan nilai indeks keragaman jenis karena berhubungan dengan terganggunya struktur komunitas seperti berkurangnya kekayaan jenis, terganggunya keseimbangan struktur komunitas dan pergeseran dominasi jenis ikan yang tertangkap.
Menurut Naamin (1984), fenomena berlimpahnya hasil tangkapan yang bukan menjadi target, mengindikasikan keanekaragaman jenis telah berubah akibat pengaruh tekananan penangkapan. Berdasarkan hal tersebut maka salah satu strategi pengelolaan yang disarankan di perairan Tarakan adalah mengalihkan daerah penangkapan dengan trawl ke tengah atau perairan yang lebih dalam (100-200 meter). Pada saat ini daerah penangkapan dengan trawl terutama pada kedalaman 10-30m. Upaya lain adalah pengendalian trawl melalui pembatasan atau pengurangan jumlah kapal trawl yang sekarang beroperasi di perairan Tarakan.

\section{KESIMPULAN}

Struktur komunitas ikan demersal di Tarakan telah berubah akibat tekanan eksploitasi yang tinggi. Status keanekaragaman jenisnya termasuk kategori sedang, jumlah 86 spesies. Sifat penyebarannya sebagian merata dan tidak banyak spesies yang mendominasi kelimpahannya.

\section{DAFTAR PUSTAKA}

Allen,G., R.Swainston \& J.Ruse, 2000. Marine fishes of south-east Asia., Periplus Edition (HK) Ltd. Singapore. 292 p.

Barus, H. R \& Mahiswara. 1994. Perikanan jaring dogol di Kalimantan Timur. Jurnal Penelitian Perikanan Laut No. 85. Balitkanlut, Jakarta. 54-68.

Badrudin, Sasanti, R. Suharti, Yahmantoro, \& S. Imam. 2003. Indeks kenaekaragaman hayati ikan kepe-kepe (Chaetodontidae) di perairan Wakatobi, Sulawesi Tenggara, Jur. Penel. Perik. Ind., Edisi Sumber Daya dan Penangkapan. 9. (7). 67-73.

Badrudin \& Karyana. 1993. Proporsi komposisi hasil tangkapan sampingan pukat udang di perairan Maluku-Irian Jaya. Jurnal Penelitian Perikanan Laut No. 79. Balitkanlut, Jakarta. 14-23.

BRPL. 2006. Pengkajian stok sumberdaya ikan demersal di perairan Banda Aceh pasca tsunami, Laporan Teknis Intern, Balai Riset Perikanan Laut Jakarta. 63 hal.

BPPL. 2001. Kajian sumberdaya ikan di perairan Laut Arafura. Laporan survey Balai Riset Perikanan Laut. Departemen Kelautan dan Perikanan. Jakarta. vi+86 hal, (tidak dipublikasikan).

Carpenter, K. E \& V. H. Niem. 1999a. The living marine resources of the Western Central Pacific. Volume 3. Botoid Fishes, Chimaeras and Bony Fishe Part 1 (Elopidae to Linophyrnidae). FAO Species 
Identification Guide for Fisheries Purposes. FAO, Rome. 1349-2068.

Carpenter, K. E \& V. H. Niem. 1999b. The living marine resources of the Western Central Pacific. Volume 4. Bony Fishes Part 2 (Mugillidae to Carangidae). FAO Species Identification Guide For Fisheries Purposes. FAO of The United Nations, Rome. 2069-2790.

Carpenter, K. E \& V. H. Niem. 2001a. The living marine resources of the Western Central Pacific. Volume 5. Bony Fishes Part 3 (Menidae to Pomacentridae). FAO Species Identification Guide For Fisheries Purposes. FAO, Rome. 2791-3510.

Carpenter, K. E \& V. H. Niem. 2001b. The living marine resources of the Western Central Pacific. Volume 6. Bony Fishes Part 4 (Labridae to Latimeriidae), Estuarine Crocodiles, sea turtles, sea snakes, and marine mammals. FAO Species Identification Guide For Fisheries Purposes. FAO, Rome. 3511-4232.

Fischer, W \& P. J. P. Whitehead. 1974. FAO species identification sheet for fishery purposes. Eastern Indian Ocean and Western Central Pacific. Vol. I-IV. FAO. Rome. $123 \mathrm{p}$.

Gloefer, T. T \& P. J. Kailola. 1985. Trawled Fishes of Southern Indonesia and Northern Australia. Directorate General of Fisheries, Indonesia. 406 pp.

Heemstra, P. C, \& J. E. Randall. 1973. FAO Species Catalogue, Vol.16, Grouper of the world (Family Serranidae, Subfamily Epinephelinae). An annoted and illustrated catalogue of the grouper, rockod, hind, coral grouper and lyretail species known to date. FAO. Fish. Syn. No.125, vol.16, Rome, FAO. 382 pp.

Krebs, C. J. 1989. Ecological methodology. Harper Collins Publisher, New York. 63 p.

Ludwig, J. A \& J. F. Reynolds. 1988. Statistical ecology : A primer on methods and computing. John Wiley \& Sons. New York. xii+337 hal.

Mansoor.M. I., Kohno, H. Ida, Nakamura, H. T., Asnan, Z \& S. Abdullah. 1998. Field guide to important commercial marine fishes of the South China Sea. SEAFDEC MFRDMD/SP/2. $136 \mathrm{p}$.

Mulyadi, E., J. Saptoyo, Nuryadi \& A. Tofani. 2005. Identifikasi Sumberdaya ikan demersal di perairan perbatasan Timur Kalimantan, Laporan teknis intern, BPPI, Semarang. 36 hal.
Naamin, N. 1977. Perkembangan perikanan udang di Indonesia. Prosiding Seminar II Perikanan udang. Maret 1977. LPPL. Jakarta. 55-65.

Naamin, N. 1984. Dinamika populasi udang jerbung (Penaeus merguiensis de Man) di perairan Arafura dan alternatif pengelolaannya. Disertasi Doktor pada Fakultas Pasca Sarjana, IPB Bogor. 381 hal.

Nakabo, T. 2000. Fishes of Japan, with pictoralkeys to the species, English edition, I and II, Tokay Univ.Press, Tokyo. $1.749 \mathrm{pp}$.

Odum, E.P., 1971. Fundamental of ecology., W.E.Sounders, Philadelphia. 567 pp.

Pielou, I. C. 1976. The Measurement of Diversity in Different Type of Biologycal Collection, Jour.Biol. 13. 131-144.

Rahmat, B. 2007. Keanekaragaman dan pendugaan kepadatan stok ikan demersal dengan menggunakan metode sapuan di perairan Aru-Propinsi Maluku, Tesis Pasca Sarjana, Fakultas Matematika dan Ilmu Pengetahuan Alam, Univ. Indonesia.

Sadhotomo, B., Wejatmiko, Suwarso, Karsono, W., M. Natsir, Asep, P., Ernawati, T., K. Amri, Herlisman \& Sudjianto, 2005. Riset bio-ekologi pelagis besar dan demersal di perairan Laut Flores, Selat Makassar dan sekitarnya. Laporan Akhir, Balai Riset Perikanan Laut Jakarta. 65 hal.

Sumiono, B. \& B. E. Priyono. 1998. Sumber daya udang penaeid dan krustasea lainya dalam Widodo, J., K. A. Azis, B. E. Priyono, GH. Tampubolon, N. Naamin \& A. Djamali (Eds.). Potensi dan penyebaran Sumber daya ikan laut di perairan Indonesia. Komisi Nasional Pengkajian Stok Sumber Daya Ikan Laut - LIPI. 71 hal.

Sumiono, B \& A. Djamali. 2006. Pemanfaatan sumberdaya udang dan ikan demersal di perairan perbatasan Nunukan - Tawau, Kalimantan Timur. Prosiding Hasilhasil Penelitian Ekosistem Terumbu Karang Sapa Segajah dan Ekosistem Muara Kalimantan Timur. Fakultas Perikanan dan Ilmu Kelautan UnMul Bappeda Pemprov Kalimantan Timur - PRPT, BRKP P2OLIPI. 130-147.

Suman, A., Badruddin, Sri Turni, H., B. Sumiono, Indar, S. W., Nuraini, S., Awwaludin, Feni, E., \& T. Ernawati. 2005. Riset pengkajian stok, life history dan dinamika populasi sumberdaya ikan demersal dan udang penaeid di Laut Cina Selatan, Laut Jawa dan Selat Makasar. 
Laporan Akhir Tahun, Balai Riset Perikanan Laut Jakarta. 142 hal.

Sparre, P. \& S. C. Venema. 1992. Introduction to tropical fish stock assessment. FAO Fish. Tech. Paper. No. 361/ 1.

Suprapto, B. Sumiono, A. Suman, Wedjatmiko, T. Ernawati, D. D. Kembaren, A. Damora, P. Lestari, B. Sadhotomo, Nurulludin, M. Rijal, R. Setiawan, A. Diatmoko, A. Surahman \& Suwardi. 2012. Penelitian stok dan pengusahaan sumber daya udang penaeid dan krustasea lainnya di WPP 713 Selat Makasar, Laut Flores dan Teluk Bone, Laporan Tahunan, Balai Penelitian Perikanan Laut, Jakarta. 75 hal.
Suprapto. 2008. Indeks keanekaragaman hayati ikan demersal di perairan Arafura, Jur. Penel. Perik. Indonesia. 14 (3). 12 hal.

Sutarto, Budiman, Joko. S \& Eris, M. 2007. Kajian sumber daya ikan demersal di perairan Selatan Kalimantan. Laporan Teknis Intern BBPPI Semarang. 42 hal.

Tandipayuk, L. S. \& T. Haryati. 1986. Keanekaragaman hayati untuk pendugaan status perairan. Pelatihan Ekologi Perikanan, Universitas Hasanudin Ujung Pandang. 26 hal. 